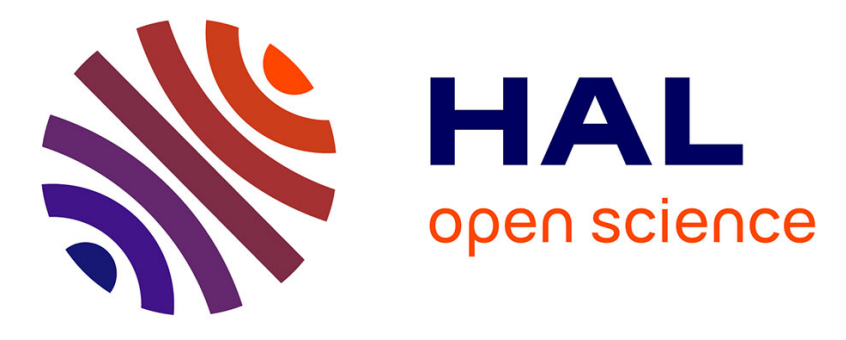

\title{
Managing events to improve situation awareness and resilience in a supply chain
}

\author{
Audrey Fertier, Guillaume Martin, Anne-Marie Barthe-Delanoë, Julien \\ Lesbegueries, Aurelie Montarnal, Sébastien Truptil, Frederick Benaben, \\ Nicolas Salatge
}

\section{To cite this version:}

Audrey Fertier, Guillaume Martin, Anne-Marie Barthe-Delanoë, Julien Lesbegueries, Aurelie Montarnal, et al.. Managing events to improve situation awareness and resilience in a supply chain. Computers in Industry, 2021, 132, pp.103488. 10.1016/j.compind.2021.103488 . hal-03272000

\section{HAL Id: hal-03272000 https://imt-mines-albi.hal.science/hal-03272000}

Submitted on 28 Jun 2021

HAL is a multi-disciplinary open access archive for the deposit and dissemination of scientific research documents, whether they are published or not. The documents may come from teaching and research institutions in France or abroad, or from public or private research centers.
L'archive ouverte pluridisciplinaire HAL, est destinée au dépôt et à la diffusion de documents scientifiques de niveau recherche, publiés ou non, émanant des établissements d'enseignement et de recherche français ou étrangers, des laboratoires publics ou privés. 


\title{
Managing events to improve situation awareness and resilience in a supply chain
}

\author{
Audrey Fertier ${ }^{\mathrm{a}, *}$, Guillaume Martin ${ }^{\mathrm{a}}$, Anne-Marie Barthe-Delanoë ${ }^{\mathrm{a}}$, Julien Lesbegueries ${ }^{\mathrm{a}}$, \\ Aurélie Montarnal ${ }^{\mathrm{a}}$, Sébastien Truptil ${ }^{\mathrm{b}}$, Frédérick Bénaben ${ }^{\mathrm{a}}$, Nicolas Salatgé ${ }^{\mathrm{a}}$ \\ a Centre Génie Industriel, Université de Toulouse, IMT Mines Albi, France \\ ${ }^{\mathrm{b}}$ CEA Tech Occitanie, Labège, France
}

Keywords:

Decision support systems

Complex event processing

Supply chain event management

Big Data

Metamodeling

Situation awareness

\begin{abstract}
A B S T R A C T
This paper aims at improving supply chain resilience by applying a model- and event-driven architecture from the crisis management field: the AIC information system which Acquires, Interprets and Contextualizes events. It begins with a literature review on information systems able to process events in order to improve situational awareness within supply chains. It concludes that supply chain managers still lack a decision support system able to access new information in near real time. The paper describes the components of the AIC information system, and the implications for a supply chain use case. By testing the architecture on a pharmaceutical supply chain, we assess the accuracy, cost and speed of the detection of new risks. These works are made possible by the use of several data streams aggregated into a single decision-making platform. This supports the claim for a more connected supply chain. Our contributions make crisis management knowledge available to supply chain management and help improving resilient decision-making in a fast changing context.
\end{abstract}

\section{Introduction}

The recent pandemic events, as well as the various natural or human-induced disasters that occurred in the last decade have showed that supply chains were not always ready to endure harsh setbacks. Charles et al. $(2010,2016)$ works put the emphasis on such a problem and help build upon the humanitarian experience, in order to move towards a better supply network. In domains as varied as humanitarian aid or emergency transportation (as shown in (Baharmand et al., 2017) or (Laguna-Salvadó et al., 2019)), we witness an increasing demand for agile and efficient decision-making under the high stress of unexpected catastrophes. These works, along with others, shed the light on a common problematic shared by logistics in times of crises: supply chains need to become more resilient if they want to provide an adequate service level and survive through the events.

\footnotetext{
* Corresponding author.

E-mail addresses: audrey.fertier@mines-albi.fr (A. Fertier), guillaume.martin@mines-albi.fr (G. Martin), anne-marie.barthe@mines-albi.fr (A.-M. Barthe-Delanoë), julien.lesbegueries@mines-albi.fr (J. Lesbegueries), aurelie.montarnal@mines-albi.fr (A. Montarnal), sebastien.truptil@cea.fr (S. Truptil), frederick.benaben@mines-albi.fr (F. Bénaben), nicolas.salatge@mines-albi.fr (N. Salatgé).
}

Resilience is the ability of a system to detect, adapt and react to disturbances in order to restore its original structure and functions as found in (Ponomarov and Holcomb, 2009; Ambulkar et al., 2015). Moreover, the resilience of a supply chain benefits from good risk management (Kamalahmadi and Parast, 2016). The objective is then to invest in order to better detect and manage risks, without exceeding the costs induced by these risks. This leads to the problematic of this paper: 'how to detect potential risks to speed up the reaction of supply chains and thus make them more resilient?'.

Fortunately, the advent of generalised digitisation brings a oneof-a-kind opportunity to make a meaningful progress towards resilience. New data and information are continuously made available by the digitisation, the cyber-physical systems and the Internet of Things of the Industry 4.0 paradigm. The integration of these technologies in logistics promises real-time monitoring and accurate risk management (Hofmann and Rüsch, 2017). However, a greater volume of data and information is not necessarily correlated with a better understanding of the situation. To deal with this, we propose to improve the situation awareness of the logistics managers: the perception of relevant information, the understanding of their meaning and the prediction of future events, as defined by Endsley $(1995,2012)$.

A greater volume of data and information also brings issues linked to the three (Schoenherr and Speier-Pero, 2015), four (Richey 
et al., 2016) or five Vs of Big Data (Papadopoulos et al., 2017; Pramanik et al., 2017). This paper refers to the 4 Vs defined in (Fertier et al., 2019): the Volume, Variety, Velocity and Veracity of data and information processed inside an information system. The data, generated for example by sensors, provide only a limited value and must be processed to generate information. As a definition of information, Mörth et al. (2020) point out that a piece of information is more valuable than the data composing it.

To transfer information between systems, we also need a decision support system interoperable with other information systems. Chen et al. (2008) defines interoperability as the ability of two systems to understand one another and to use functionalities of one another. To do this, the information systems can all refer to a common set of explicit concepts called ontology, as proposed by $\mathrm{Gu}$ et al. (2005). This enables to model an information set, describing for example a supply chain, independently from any programming language, operating systems or middlewares.

In this context, with the aim to answer our problematic, the research works in this paper seek to build a decision support system which

1. Continuously acquires and analyses numerous and varied data, in order to monitor a supply chain and detect new risk or opportunities in real time;

2. Refers to an ontology, in order to store interoperable and activable information describing the current situation;

3. Limits the negative effects of the Volume, Variety, Veracity and Velocity of data and information processed, in order to properly enhance the situation awareness of the end-users.

Section 2 reviews the literature on information systems capable of process data and detect risks in real time. However, no information system applied to supply chains seems to suit the needs stated in this introduction. To fill this gap, Section 3 presents an information system inherited from the crisis management field. Section 4 presents the decision support system implementing this information system. Section 5 presents a pharmaceutical supply chain use case. Finally, Section 6 qualitatively and quantitatively assesses the results of the decision support system on the supply chain use case.

\section{Literature review}

This section seeks information systems capable of continuously acquires and analyses any kind of data streams in order to monitor a supply chain and detect, as fast as possible, potential risks to speed up its reaction and make it more resilient.

The literature review is based on the Core collection of the WebOfScience database, from 1975 to 2020, on Topics. The Topics include the title, the abstract, the author keywords and the Keywords Plus added by the database. Table 1 presents the query. It is composed of three parts, linked by the AND operator. The query searches for research papers in the logistics domain [1], aiming to either enhance the situation awareness of their users, populate an ontology, update a model or detect risks and opportunities [2], using data or event processing [3].

The Query returned 38 articles among the $400 \mathrm{k}$ articles returned by the parts [1] or [2] or [3]. Of these, we selected $22(58 \%)$ on the basis of their abstract and 9 (24\%) on the basis of their full text. In the light of our problematic, we only kept the information systems processing data streams to deduce or update information. The articles also had to demonstrate their implementation on a logistics case study.

We evaluated the resulting 9 articles according to four criteria related to the issues linked to the $5 \mathrm{Vs}$ of Big Data. They are all listed below. They concern both the data (text or events) in input and the information, in output, intended for the logistics managers. As defined in the introduction, information are deduced from data, and a piece of information has more value for the decision-maker than the data composing it.

- Volume: do they filter data or information according to its usefulness?

- Variety: do they process more than one type of data? do they deduce more than one type of information?

- Velocity: is the input data processed, or the information updated in near-real time?

- Veracity: do they control the veracity of processed data or interpreted information?

Table 2 summarises the evaluation. The articles are in rows. The second column indicates if they use event driven architectures (eda), natural language processing ( $n l p)$ or ontologies $(0)$. The next four columns represent a criterion. Each criterion can be satisfied when data (D) or information (I) are processed. The last column sums the number of times the data or information processed are concerned by one of the criteria.

The five first papers of the table describe how event driven architectures allow to filter incoming events and manage various events streams in parallel. Three of them couple it with an ontology:

- Overbeek et al. (2012) use (i) complex event processing to infer new information and (ii) this new information to execute, manage and monitor business processes inside a supply chain. All the complex events, information and services are stored and described inside a dedicated ontology.

- Tejada and Jung (2013) use complex event processing to monitor data streams coming from temperature, humidity and $\mathrm{CO}_{2}$ sensors. They aim to preserve food quality in a cold chain logistics. They use an ontology to store knowledge of interest for the food chain logistics.

- Kim et al. (2016) use event processing to monitor a freezer truck through the analysis of data streams coming from a RFID reader, a door sensor and a temperature sensor. They use an ontology to store and combine information on context identification, risk evaluation and response detection.

Vlahakis et al. (2018) couple a complex event processing engine with a graph-oriented data based to monitor a supply chain. But, as the event driven architecture proposed by Danila et al. (2016) or the weather-related traffic incident perception proposed by Lu et al. (2018), information describing their context do not seem to refer to an ontology. Ontologies enable the representation of complex contexts (Perera et al., 2014). Coupled with event driven architecture, an ontology would have enable the definition of complex business rules and therefore more specific, contextualized, analyses of incoming events.

The most interesting papers, with the higher marks, are detailed in Table 3. The articles are in rows. The second, respectively third, column lists the data, respectively information, processed in the case study of the article. The fourth column lists the additional contextual information used during the interpretation process of the case study.

Tejada and Jung (2013), Kim et al. (2016) focus on internal data coming from RFID systems or sensors. We aim to enlarge this scope, by allowing logistics managers to access other events, coming from external data sources or external services. This idea is close to the one developed by Vlahakis et al. (2018), but their information system only issues alerts. We aim to go further; our objective is to detect as fast as possible potential risks by acquiring and analysing any kind of data stream, in order to speed up the reaction of supply chains and make them more resilient. 
Table 1

The query used on the WebOfScience Core Collection, searched by Topic, from 1975 to 2020, on December 21, 2020. Abbreviations: Op. Operator, Nb. Number

\begin{tabular}{|c|c|c|}
\hline Op. & $\mathrm{Nb}$. & Part of the query \\
\hline & {$[1]$} & $\begin{array}{l}\text { ("logistics" OR "supply chain*" OR "cold chain*" OR "freight transport*" OR (("monitoring" OR "planning" OR } \\
\text { "management") NEAR/1 (route OR transport*))) }\end{array}$ \\
\hline AND & [2] & $\begin{array}{l}\text { ("situation* aware*" OR "context* aware*" OR "operational picture*" OR ontolog* OR "meta-model*" OR } \\
\text { metamodel* OR "model-based" OR "model-driven" OR (detect* NEAR/1 (risk* OR alert* OR disturbance* OR } \\
\text { "unexpected situation*" OR "unexpected event*" OR accident* OR incident* OR congestion OR queue))) }\end{array}$ \\
\hline AND & [3] & $\begin{array}{l}\text { (("event"" OR "data" OR "stream*" OR "language" OR "flow" OR "text") NEAR/1 ("processing" OR "fusion" OR } \\
\text { "analytics" OR "reasoning")) OR "event-based" OR "event-driven") }\end{array}$ \\
\hline
\end{tabular}

Table 2

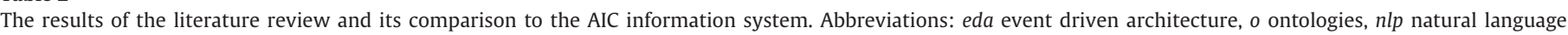
processing, D data, I information, n.a. not available.

\begin{tabular}{|c|c|c|c|c|c|c|}
\hline Article & & Volume & Variety & Velocity & Veracity & Count \\
\hline Overbeek et al. (2012) & eda, o & - & $\mathrm{D}$ & $\mathrm{D}$ & - & 2 \\
\hline Tejada and Jung (2013) & eda, o & $\mathrm{I}$ & $\mathrm{D}, \mathrm{I}$ & $\mathrm{D}, \mathrm{I}$ & - & 5 \\
\hline Kim et al. (2016) & eda, o & $\mathrm{D}, \mathrm{I}$ & $\mathrm{D}, \mathrm{I}$ & $\mathrm{D}, \mathrm{I}$ & - & 6 \\
\hline Danila et al. (2016) & eda & $\mathrm{D}$ & $\mathrm{D}$ & $\mathrm{D}$ & - & 3 \\
\hline Vlahakis et al. (2018) & eda & $\mathrm{D}, \mathrm{I}$ & $\mathrm{D}, \mathrm{I}$ & $\mathrm{D}, \mathrm{I}$ & - & 6 \\
\hline Lu et al. (2018) & $n l p$ & $\mathrm{D}, \mathrm{I}$ & $\mathrm{D}$ & $\mathrm{D}, \mathrm{I}$ & - & 5 \\
\hline Wen et al. (2018) & n.a. & $\mathrm{D}, \mathrm{I}$ & $\mathrm{D}$ & $\mathrm{D}, \mathrm{I}$ & - & 5 \\
\hline Basdere et al. (2019) & n.a. & - & $\mathrm{D}, \mathrm{I}$ & I & - & 3 \\
\hline orth et al., 2020 & $n \cdot a$ & - & $\mathrm{D}, \mathrm{I}$ & $\mathrm{D}, \mathrm{I}$ & - & 4 \\
\hline
\end{tabular}

Table 3

The more interesting results of the literature review. Abbreviations: D data, I information.

\begin{tabular}{|c|c|c|c|}
\hline Article & input (D) & output (I) & additional (I) \\
\hline Tejada and Jung (2013) & temperature, humidity, $\mathrm{CO}_{2}$ & jar of ice cream expired or to expire soon & expiration date \\
\hline Kim et al. (2016) & RFID, temperature, door state & - & - \\
\hline Vlahakis et al. (2018) & strike, failure, weather, economic and traffic events & complex event & - \\
\hline
\end{tabular}

Table 4

The AIC information system evaluated for the criteria of the literature review. Abbreviations: D data, I information.

\begin{tabular}{|c|c|c|c|c|c|c|}
\hline Article & & Volume & Variety & Velocity & Veracity & Mark \\
\hline Fertier et al. (2020) & eda, o & $\mathrm{D}, \mathrm{I}$ & $\mathrm{D}, \mathrm{I}$ & $\mathrm{D}, \mathrm{I}$ & - & 6 \\
\hline Article & input (D) & \multicolumn{3}{|c|}{ output (I) } & \multicolumn{2}{|l|}{ additional (I) } \\
\hline Fertier et al. (2020) & \multicolumn{2}{|c|}{$\begin{array}{l}\text { water level, water flow, } \\
\text { traffic measurements }\end{array}$} & $\begin{array}{l}\text { flooded area, ris } \\
\text { absence of evac }\end{array}$ & & \multicolumn{2}{|c|}{$\begin{array}{l}\text { presence of sensitive buildings in a } \\
\text { danger zone }\end{array}$} \\
\hline
\end{tabular}

To do this, we propose to evaluate an existing research work from crisis management, on a logistics case study. This research is based on the AIC information system presented by Fertier et al. (2020) and evaluated in Table 4. It is based on a specific eventand model- driven architecture, coupled with a specific ontology called meta-model which is composed of all the concepts that can be used to model a collaborative situation. The information system interprets $m$ types of data to update the model with $n$ types of information, composed of $\mathrm{p}$ attributes, in real time to update the information describing the context of the collaboration.

This article tests the AIC information system, based on a specific event and model-driven architecture and ontology, in the logistics field. We aim to provide an answer to the problematic stated in the introduction: how to detect potential risks to speed up the reaction of supply chains and thus make them more resilient?. However, we note that logistics managers will still lack solutions to check the veracity of the data or information they process.

First, Section 3 presents the AIC information system architecture. Next, Section 4 presents the R-IOSUITE decision support system which already implements the AIC information system. Then, Section 5 presents how the AIC information system, via RIOSUITE, can be used to improve the situation awareness of logistics manager in real time. Sections 6 and 7 evaluate and discuss the results of the experimentation.

\section{The AIC information system}

\subsection{The framework}

Fig. 1 presents the - event and - model driven architecture enabling the AIC information system to acquire, interpret and contextualise data. This data is used to update the model of a collaborative situation as a supply chain. All its components are described below.

To constantly monitor the environment, a system has to acquire data, like RFID data or crash reports. It either makes a request periodically to sensor hardware (Pull) or subscribe to a data source which pushes data periodically or instantly (Push). The AIC information system implements the second option: a publish/subscribe mechanism based on topics. Fig. 1 features a message broker which subscribes to data sources and receives events. An event is a piece of data consisting at least, of an ID, a timestamp and a description. The data sources can be internal or external to the decision support system using the AIC information system.

The AIC information system uses a Complex Event Processing (CEP) engine to interpret and contextualise events. As described by Luckham and Frasca (1998) and Flouris et al. (2017), a Complex Event Processing engine processes data efficiently, at multiple levels of abstraction, to immediately recognise interesting situations 


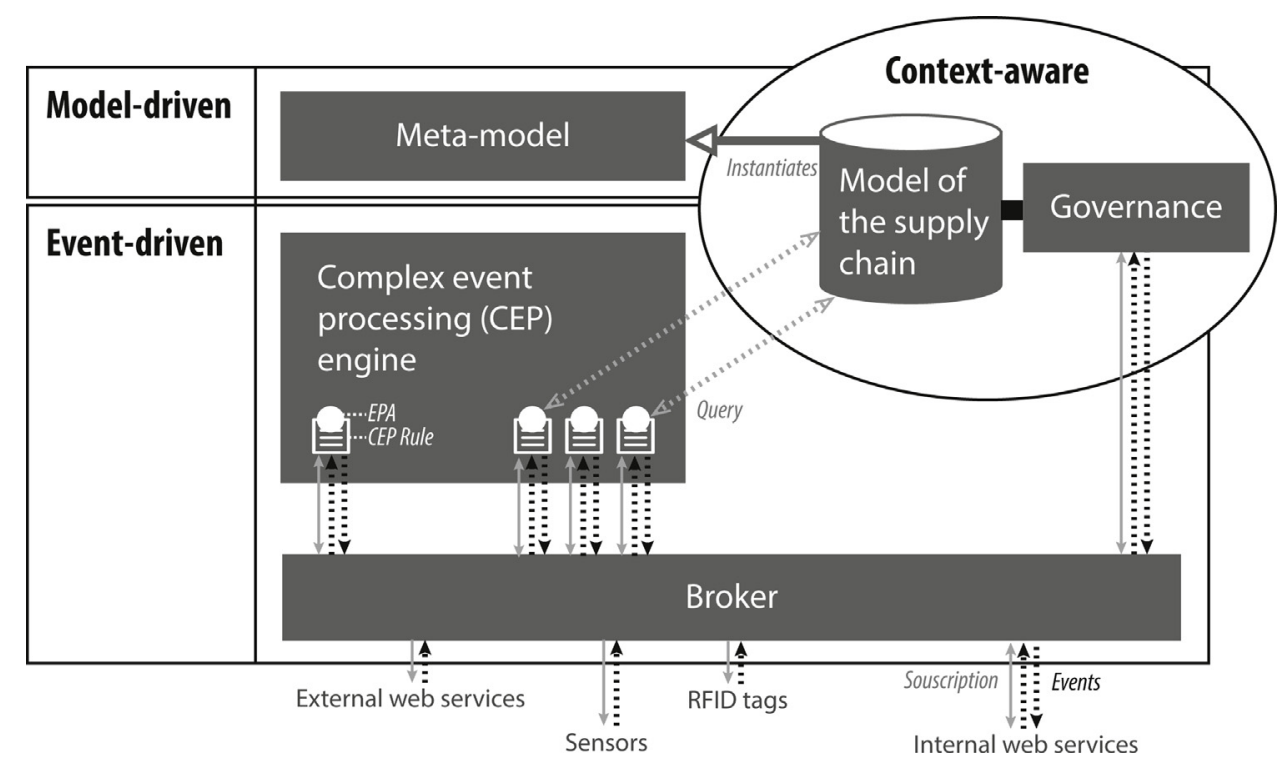

Fig. 1. Architecture of the AIC information system. Abbreviations: CEP Complex Event Processing, EPA event processing agent, RFID radio frequency identification.

when they occur. The event processing relies on Complex Event Processing agents linked to a set of Complex Event Processing rules. A rule subscribes, via the broker, to topics of interest, rather than direct subscription to each single data source. It activates when patterns match the presence or absence of certain events, in given time windows. When activated, a rule generates new events, called complex events. Complex events are processed again as events through the message broker; events may be handled by an infinite number of rules. In addition, events can be filtered by conditions.

A Complex Event Processing engine is represented in Fig. 1. The events (complex or not) all come from and are sent to the message broker. External events can be received from web services, RFID readers, or sensors through the publish/subscribe mechanism. Each rule is written manually, but not necessarily by the end-user. The AIC's CEP rules represent the business knowledge that organisations in the supply chain have on how to detect risks and incidents which may affect them.

The main contribution of the AIC information system enables its CEP rules to query the current state of the supply chain model. This enables a context-aware supply chain chain event management, and therefore an automatic context-aware supply chain risk management. The AIC information system is flexible enough to easily adapt to all kind of data streams, business rules or information from any kind of supply chains.

\subsection{The AIC's ontology}

The AIC information system refers to an ontology to represent any kind of supply chain contexts. When a business rule, represented by CEP rules, detects a new danger, risk or incident, it can emit a complex event that asks for the instantiation of a part of the ontology.

The AIC's ontology is called the CORE meta-model. Fig. 2 presents the implemented CORE meta-model, also available at: https://r-iosuite.com/display/RIOSUITE/UML+Diagram+Release. It enables to model collaborations, like supply chains, and is inspired from the work of (Nguyen et al., 2013; Lauras et al., 2015; Benaben et al., 2020). Its representation follows the Unified Modeling Language (UML) standard as described by the Object Management Group (2017).

The AIC's ontology consists of four packages. They group the concepts by topics, described below given a supply chain context:
- the supply chain environment (description of warehouses, distribution centres, available data sources, etc.);

- the supply chain partners (description of organisations, services, functions and resources made available to meet customer requests);

- the supply chain objectives (description of customer demands, current risks and opportunities);

- the supply chain processes (description of how services can be coordinated to respond to customer requests).

\subsection{The implementation}

The message broker is implemented in Java and follows the recommendations of the OASIS standard on the web services notification (Graham et al., 2006), the Web services brokered notification (Chappell and Liu, 2006) and the Web services topics (Vambenepe et al., 2006). The publish/subscribe mechanism could also have followed other OASIS standards, such as the MQTT messaging protocol which runs over TCP/IP, but we chose to facilitate the interoperability with external web services by using a protocol running on the application layer (through HTTP).

The Complex Event Processing engine is implemented in Java and the Complex Event Processing rules are written in SIDDHI $\mathrm{QL}$, a domain specific language available at https://docs.wso2.com/ display/CEP300. The context aware supply chain event management is implemented using a function added to the native SIDDHI QL functions. It queries the Neo4J database, storing the model describing the current logistics situation.

The CORE meta-model is implemented as XML files: one for each package (environment, partners, objectives and processes). The packages can be used to offer the supply chain managers different points of views of their supply chain. All the XML files instantiate a common XSD file (XML schema).

The models, also defined in XML files, instantiate the metamodel and are stored inside a Neo4J graph data-base which is queried through the use of the Cypher query language. Neo4J is available at https://neo4j.com/ along with the Cypher documentation: https://neo4j.com/docs/cypher-refcard/current/. This database is augmented with an Application Programming Interface (API) to ensure that the model of the situation matches the implemented CORE meta-model. In Fig. 1, this API is included in the governance box. 


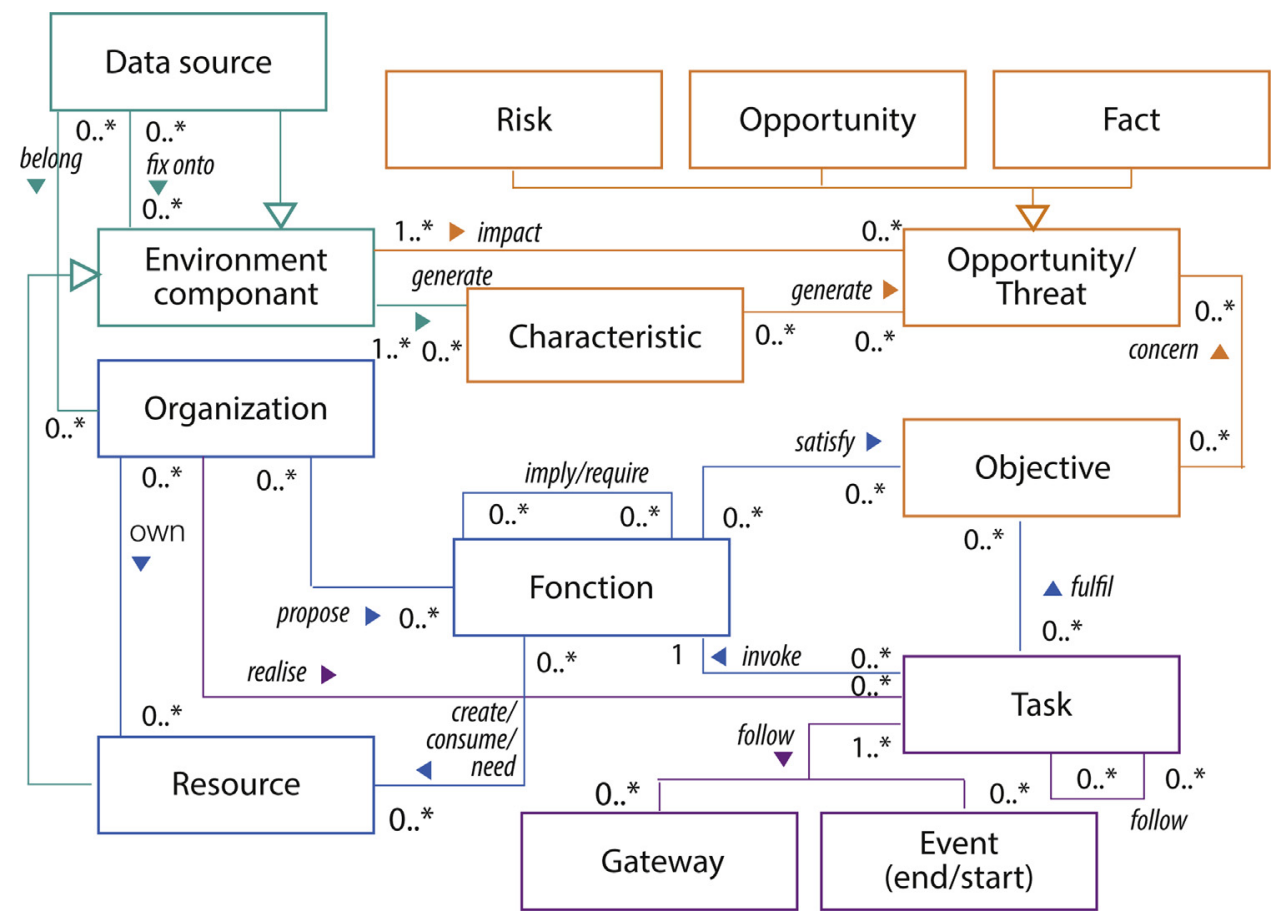

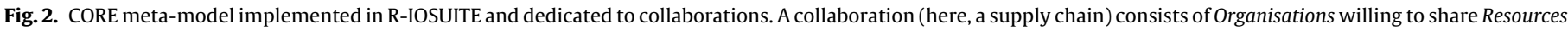

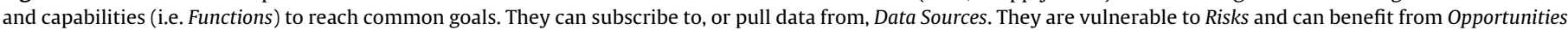

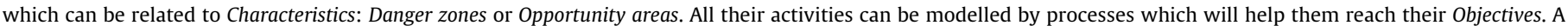
process is made of a Start event, Tasks, Gateways and an End event.

\section{The R-IOSUITE decision support system}

The AIC information system is currently implemented within a free open source tool suite called R-IOSUITE. This research prototype is developed by Salatgé et al. (2020) and available at https:// r-iosuite.com/.

\subsection{The user interfaces}

R-IOSUITE is a software prototype which consists of several applications including:

- A governance assistant, R-IOGA, which creates or loads a case study, queries the database containing the model of the supply chain (instantiating the CORE meta-model) and manages the todo list of the organisations, deduced from on-going processes.

- A geographical information system, R-IOPLAY, which locates the information of the model, describing the supply chain, on a map. It displays the current state of the model of the supply chain, loads information from external geographical information systems, or filters the visible information through layers.

- A modeler, R-IODA, which represents the same information as R-IOPLAY with a model-oriented view.

- A monitoring assistant, R-IOTA, which enables real-time monitoring of the entire supply chain. It compares what can be expected from ongoing processes to what is actually happening; it compares the supply chain as it is to the supply chain as it should be, given the current objectives and the on-going processes. This inherits from Barthe-Delanoë et al. (2014).

In line with our problematic, the AIC information system is used to automatically update the model, represented on R-IOPLAY, RIODA or R-IOTA, with new risks, opportunities, accidents or benefits detected through the analysis of data streams.

\subsection{The implementation}

The back-end is mainly developed in Java, while the front-end implements the Angular framework and was developed in TypeScript.

The binaries and source code of R-IOSUITE, composed of the AIC information system, are available at https://r-iosuite.com/display/ RIOSUITE/Downloads. The rest of this paper is based on the development version of the software. New versions of the software are released every six months.

\section{The case study}

This article tests the benefits of the AIC information system on a French pharmaceutical supply chain. This supply chain is regulated by law (L'Assemblée nationale and Le Président de la République, 2011). It aims to limit the dysfunctions which cause shortages in the supply of drugs in France. As pointed out by the French Ministry of Solidarity and Health (MSS, 2016), this supply chain is "regularly subject to malfunctions leading to disruptions in the supply of drugs for human use". A shortage is defined as the inability to supply a drug when the waiting time exceeds $72 \mathrm{~h}$. This sector, described by MSS (2017), operates by means of the collaboration of four different types of actors:

- Pharmaceutical establishments manufacture, import and sell drugs. These sales are made either directly to pharmacies, internal pharmacies or wholesaler-distributors;

- Custodians distribute drugs on behalf of pharmaceutical establishments;

- Wholesaler-distributors buy drugs from pharmaceutical establishments and resell them to pharmacies;

- Pharmacies buy the drugs they distribute. Internal pharmacies are part of hospitals and medical-social establishments. 


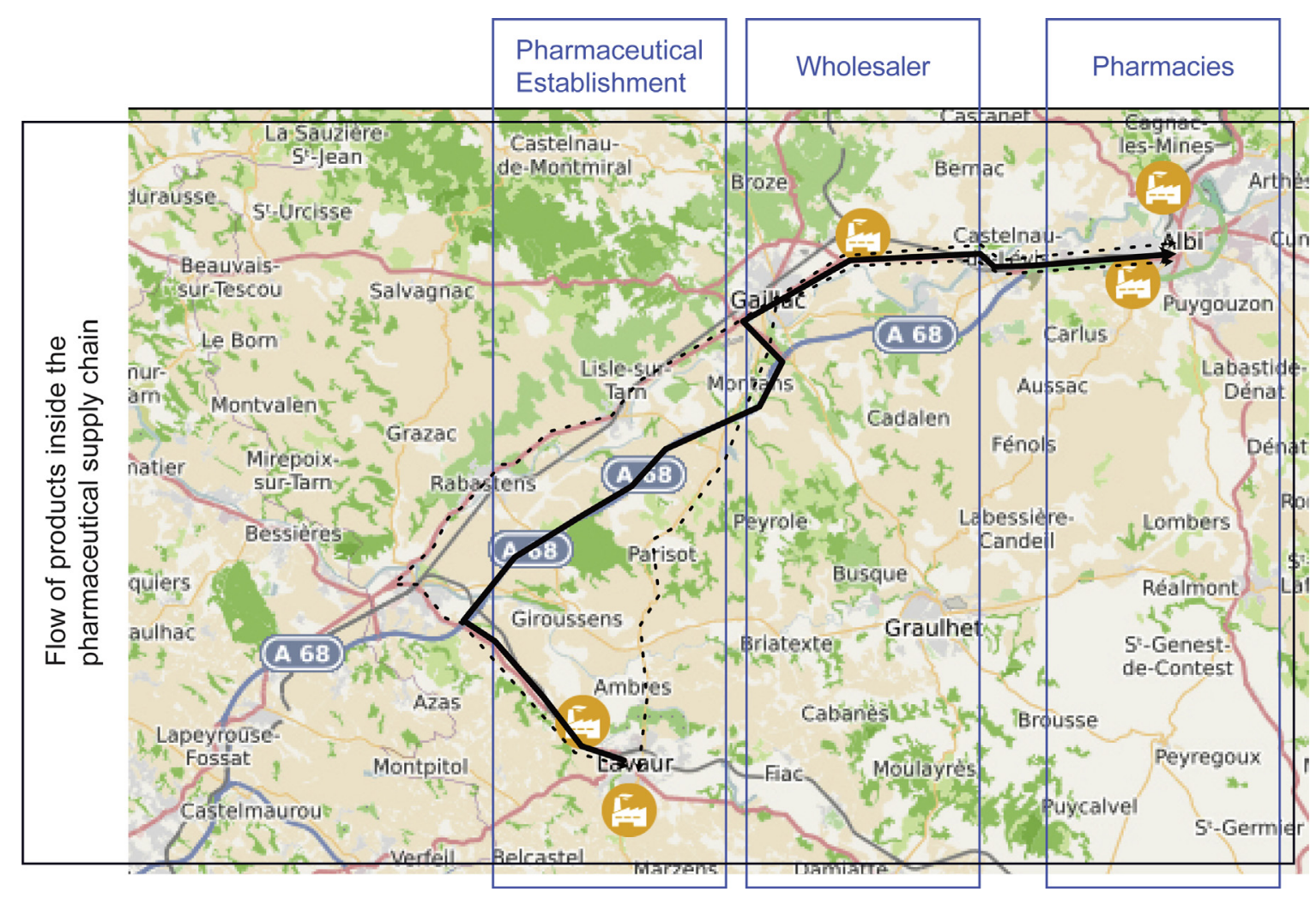

Fig. 3. The supply chain of the case study.

Fig. 3 represents the pharmaceutical supply chain of our case study. The five organisations are represented with yellow factory icons. The favourite route of the suppliers, represented by a black arrow, includes the A68 highway. Two other possible routes are represented by dotted arrows. The two pharmaceutical establishment are based in the city of Lavaur, the wholesaler in the city of Gaillac and the two pharmacies in Albi. All of these towns are in the Tarn department in southwestern France.

The AIC information system first needs information describing the environment, partners and processes of the supply chain. All these information need to be added manually, not necessarily by the end-users, at design time, to prepare the information system for the run time. The model of the supply chain can be initialised with the following instances (cf. Fig. 2), all illustrated by Fig. 4:

- Organisations: one internal pharmacy (P1), one pharmacy (P2), one wholesaler-distributor (W) and two pharmaceutical establishments (PE1, PE2), on the left side of the figure. Each is represented by a building.

- Functions: the pharmaceutical establishments manufacture and sell drugs. The pharmacies, or internal pharmacies place orders. The wholesaler-distributor supplies drugs from pharmaceutical establishments to the pharmacies and internal pharmacies. They are on the left side of Fig. 4. Each is linked to at least one organisation and is represented by a person and gears.

- Data sources: three free data sources, from open data. They subscribe to weather forecasts, traffic measurements and traffic events.

Then, at run time, every day for instance, one of the supply chain partner has to declare their ongoing orders and which delivery process will be used to fulfil them.
- Objectives: the 7th February, 2020, all the pharmacies (P1 and P2) have ordered 20 D1 and 20 D2 drugs. They are on the middle of the figure and are represented by yellow targets. The goal of the supply chain is to meet these demands.

- Tasks: a dedicated collaborative process is needed to fulfil the deliveries asked by the pharmacies. The process is on the right side of the figure. Each activity is a box with a person on it.

While the delivery processes are underway, the AIC information system automatically monitors the environment of the supply chain. The case study shows how it deduces two types of information, from three types of event streams when specific conditions are met:

- Dangers: a traffic jam area is added when traffic exceeds a certain threshold, when an accident is detected, when heavy rain is forecast or when snowfall is expected, for example.

- Risks: a risk of delay each time a delivery passes through a danger zone.

\subsection{The data}

The added value of the AIC information system lies in the discovery of risks and opportunities in near real-time. This requires the interpretation of the data coming from our three data sources. For each of them, an XML file lists all the events to be simulated the case study and evaluate the information system. We simulate a full day of events. Fig. 5 presents the first event of each XML files containing the events to be simulated for each source. All the markups are in black and the values in color. The screenshot to the right represents the data described by each event on the day of simulation.

- Weather forecast data source: the first event flow in Fig. 5 comes from the weather forecast web service. It gives the weather fore- 


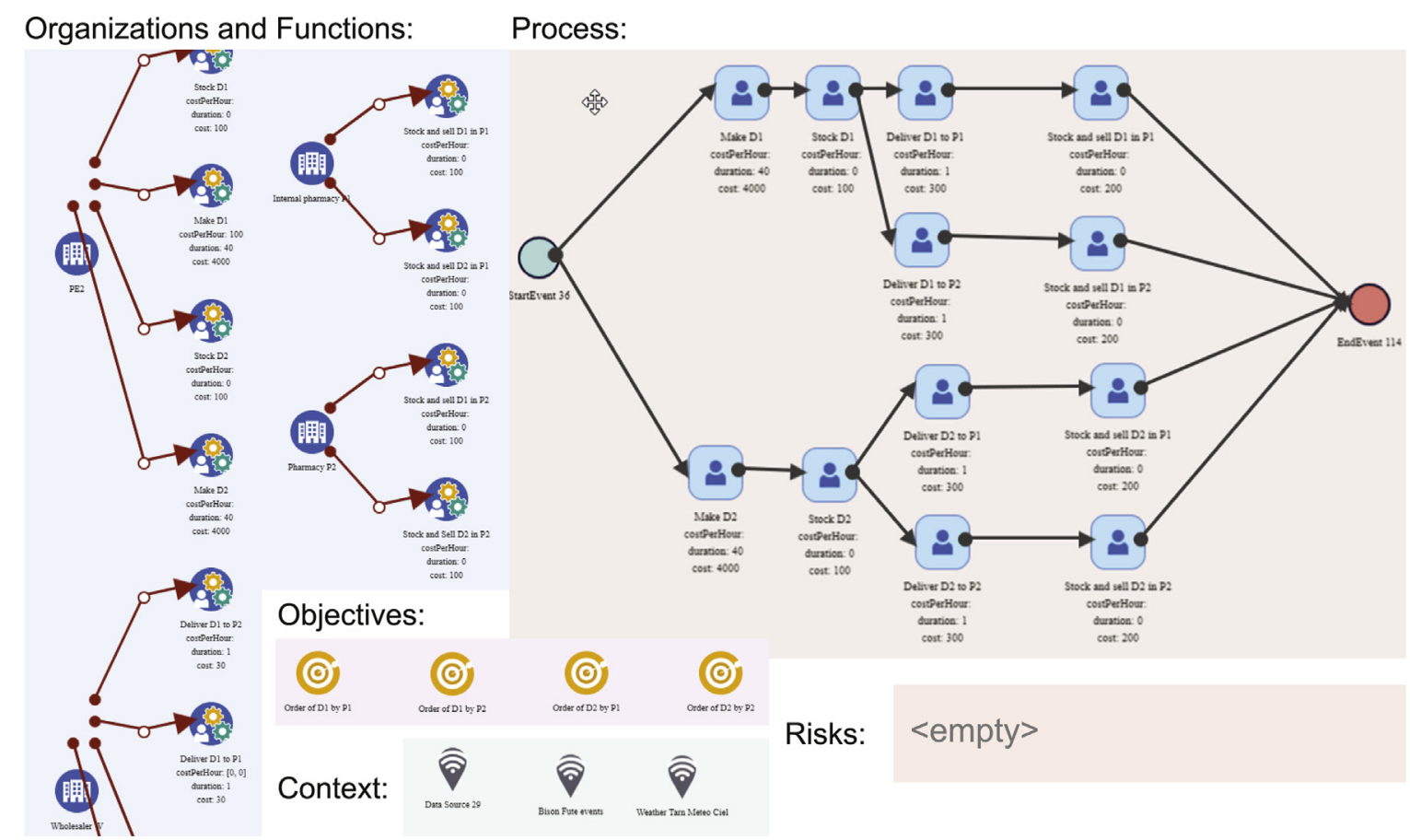

Fig. 4. The current logistics model, before the use of the AIC information system, according to five points of views: Context, Objectives, Functions, Risks, Process.

casts for the city of Gaillac, near Albi, for the next $24 \mathrm{~h}$, every $3 \mathrm{~h}$. The first four lines are common to all the events received from this web service. The first event consists of a name, an id, a timestamp and measurements. It involves a measurement for the temperature ('temp'), the wind ('vent'), the precipitation level ('pluie3h'), the humidity ('humidite'), the atmospheric pressure ('pression') and the weather (temps).

- Traffic measurements data source: the second event flow in Fig. 5 comes from the traffic event web service. It emits an event when an incident or an alert occurs from the official French Road service. In the Figure, it alerts on an incident on the A68 highway. The two other events, not represented in the Figure, alerts on a road-block and a speed limitation on road 630 . Each event specifies the type of alert (incident, speed limit or closed route), status, latitude, longitude, route number and direction.

- Traffic events data source: the last event flow in Fig. 5 comes from the traffic sensor. It emits an event containing traffic counts for $1 \mathrm{~h}$, every hour, on the A68 highway at the Gaillac interchange, in both directions: to Albi ('direction1') and to Toulouse ('direction2').

All the data contained in these events will be processed by the AIC information system before being transmitted to logistics managers. The goal is to prevent information overload while improving the situation awareness of the supply chain manager.

\subsection{The Complex Event Processing rules}

To acquire events, the AIC information system listens (i.e. subscribes) to any topic, such as "Weather Forecast", chosen by the logistics managers. Then, each event passes through every rule chosen by the logistics managers but not necessarily implemented by them. The AIC then processes and contextualises a large volume of heterogeneous event flows. To test our case study, we set up three interpretation rules and one contextualisation rule presented in the next paragraphs.
- Weather interpretation rule: the first rule in Fig. 6, listens to the 'weather' topic. It processes the 'Event_weatherForecast' of Fig. 5, the first event stream represented in Fig. 5. If snow is forecast, the rule asks for the instantiation of the Danger concept, inheriting from Characteristic (cf. Fig. 2). The Danger here is named 'Congestion', described as a 'Congestion due to snow' and located, as a blue area, on Gaillac city.

- Traffic interpretation rule: the second rule in Fig. 7, listens to the 'traffic' topic. It processes the 'Event_trafficMeasure', the last event stream represented in Fig. 5. If more than 80 vehicles are counted, one way or the other, on the A68 highway, the rule requires the instantiation of the Danger concept. It is also named a 'Congestion', described as a 'A68 traffic congestion' and located, as an orange zone, on the interchange in Gaillac city.

- Traffic event interpretation rule: the third rule in Fig. 8, also listens to the 'traffic' topic. It processes the 'Event_traffic', the second event stream represented in Fig. 5. If the event takes place in our county, the rules requires the instantiation of the Danger concept. It is again named a 'Congestion', described as a 'Congestion due to...' where the rule adds the type and location of the input traffic event to the description. It is located at the site of the input traffic event, given its latitude and longitude.

- Congestion contextualisation rule: the fourth rule in Fig. 9 listens to the 'publishModel' topic, the topic used to ask the instantiation of our meta-model. It processes the 'publishModelEvent': the event stream outputted in Figs. 6, 7 and 8. If the event type of one of its instance is a Danger called 'Congestion', and if there are ongoing delivery tasks on our collaborative process, it asks for the instantiation of the Emerging risk concept. It names it a 'Risk of Delay' and locates it at the site of the input danger instance given its latitude and longitude.

The separation of the concepts of danger and risk is another contribution of the AIC information system. The causes of dangers, and the associated rules, can multiply, while there will always be only one rule to deduce a specific type of risk, here a delay. 
$<$ ?xml version="1.0" encoding="UTF-8"?>

<ns37:dataset xmlns:xs="http://www.w3.org/2001/XMLSchema" name="Gaillac_weather">

<ns37:topicToSubscribe xmlns:ns55="http://www.mines-albi.fr/weatherTopic">ns55:WeatherTopic</ns37:topicToSubscribe>

$<$ ns37:data $>$

<Event weatherForecast xmlns="http://www.mines-albi.fr/weatherEvent">

$<i d>1<$ id $>$

$<$ date $>2020-02-07 T 02: 00: 00.000+01: 00<$ date $>$

$<$ city $>$ GAILLAC $</$ city $>$

$<$ temp $>-1</$ temp $>$

$<$ vent $>10<$ /vent $>$

$<$ pluie $3 \mathrm{~h}>4.3<$ pluie $3 \mathrm{~h}>$

$<$ humidite $>98<$ /humidite $>$

$<$ pression $>1012<$ /pression $>$

$<$ temps>neigeModeree</temps>

$</$ Event_weatherForecast>

$<$ /ns37:data $>$

$</$ ns37:dataset>

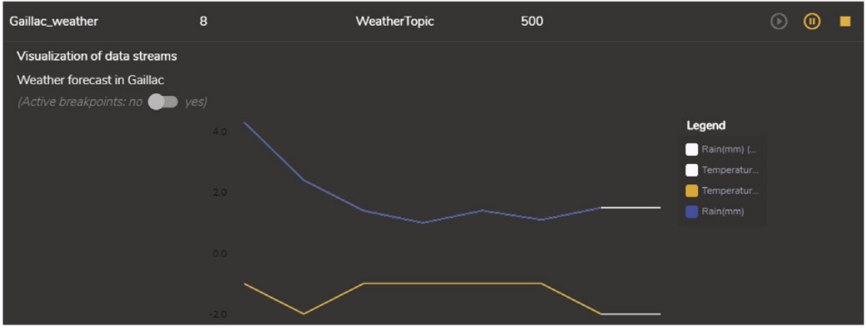

$<$ ?xml version="1.0" encoding="UTF-8"?>

<ns37:dataset xmlns:xs="http://www.w3.org/2001/XMLSchema" name="BisonFute">

<ns37:topicToSubscribe xmlns:ns55="http://www.mines-albi.fr/trafficTopic">ns55:TrafficTopic</ns37:topicToSubscribe>

$<$ ns37:data $>$

<Event_traffic xmlns="http://www.mines-albi.fr/trafficEvent">

$<$ id $>1</$ id $>$

$<$ date $>2020-02-07$ T08:00:00.000+01:00</date $>$

$<$ type>accident</type>

$<$ dep $>81</$ dep $>$

$<$ lat $>43.916386</$ lat $>$

$<$ long $>2.094205<$ /long $>$

$<$ axe $>$ A68 $<$ /axe $>$

$<$ direction $>$ Toulouse $<$ /direction $>$

$</$ Event_traffic $>$

$</$ ns37:data $>$

$</$ ns37:dataset>

$<$ ?xml version="1.0" encoding="UTF-8"?>

$<$ ns37:dataset

xmlns:xs="http://www.w3.org/2001/XMLSchema" name="A68_traffic">

<ns37:topicToSubscribe xmlns:ns55="http://www.mines-albi.fr/trafficTopic">

ns55:TrafficTopic</ns37:topicToSubscribe $>$

$<$ ns37:data>

<Event trafficMeasure xmlns="http://www.mines-albi.fr/trafficEvent">

$<$ id $>1<\overline{\text { id }}>$

$<$ date $>2020-02-07$ T01:00:00.000+01:00</date $>$

$<$ city $>$ GAILLAC $</$ city $>$

$<$ direction $1>0</$ direction $1>$

$<$ direction2 $>0</$ direction2 $>$

$</$ Event_trafficMeasure>

</ns37:data $>$

$<$ /ns37:dataset>

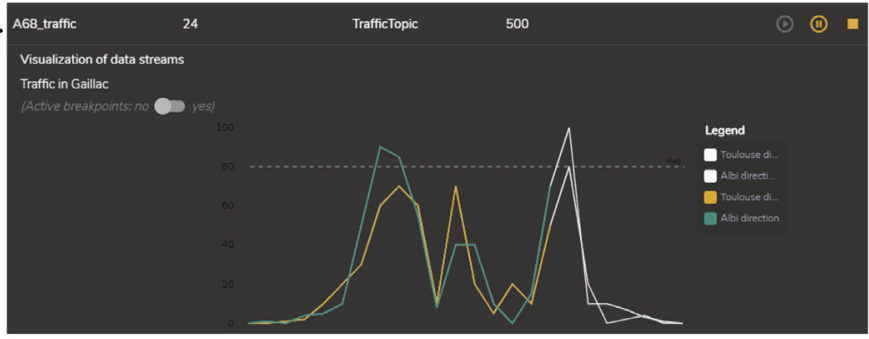

Fig. 5. The first three events of the three data sources used for the simulation of the logistics case study, along with a visualization of each stream.

\subsection{Outcome}

This use case proves that the AIC information system can continuously acquires and analyses three types of data streams in order to monitor a supply chain and detect, as fast as possible, risks of delay to speed up its reaction and make it more resilient.

The four Complex Event Processing rules of the case study enable to interpret data coming from four data sources: weather forecasts, traffic sensors, traffic events and the addition of new danger to our supply chain model. All the interpreted and contextualised instances were well named and well located. They are listed below.

- Five dangers of congestion in five different cities due to (i) weather conditions in Gaillac city, (ii) traffic conditions in Gaillac city, (iii, iv \& v) three traffic events located nearby (an accident and a road block and a speed limitation).

- Five risks of delay due to the interconnection of the ongoing distribution process and the dangers of congestion due to weather conditions, traffic conditions or traffic events.

Using the AIC information system, the delivery process can be adapted to risks which would have remained unknown without the automatic context-aware supply chain risk management. Without the AIC information system, the delivery trucks would have taken their favourite road (cf. Fig. 3), unaware of the road block or weather predictions. With the AIC information system, supply chain managers can anticipate their reactions to risks incurred both in the planning phase and during an ongoing delivery. 


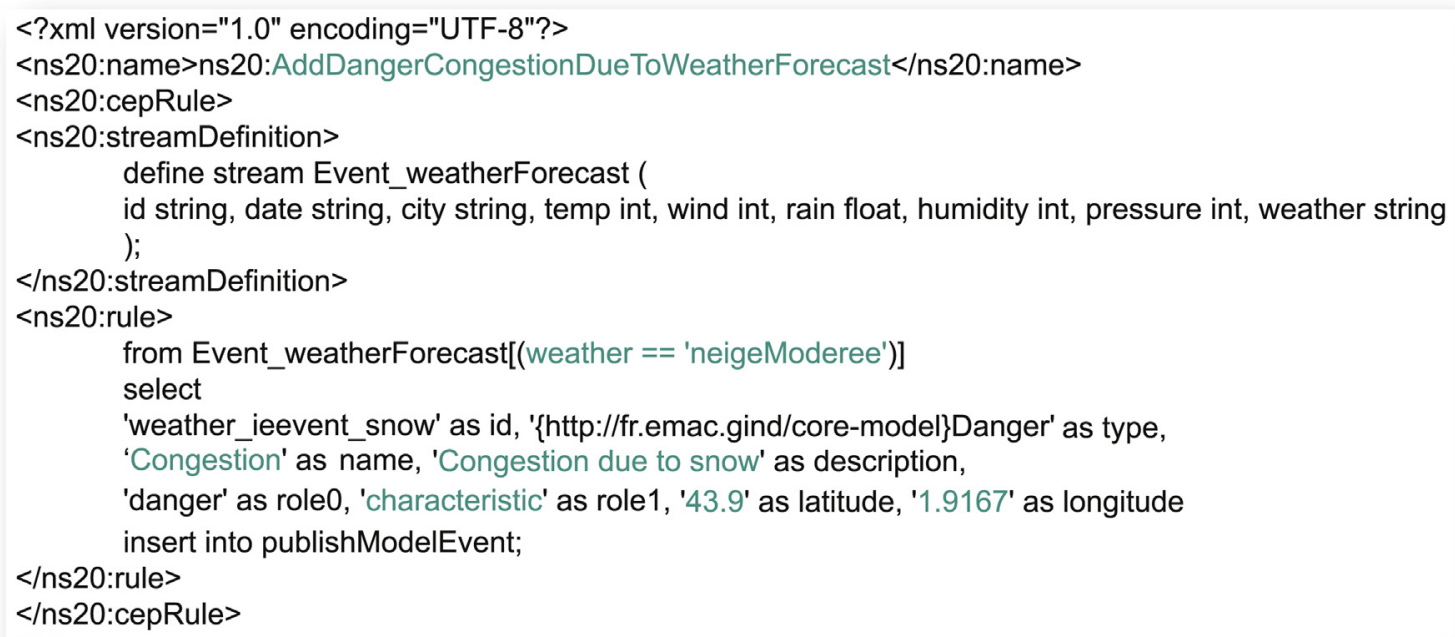

Fig. 6. The AddDangerDueToWeatherForecast interpretation rule, stored in a XML file, written in SIDDHI QL.

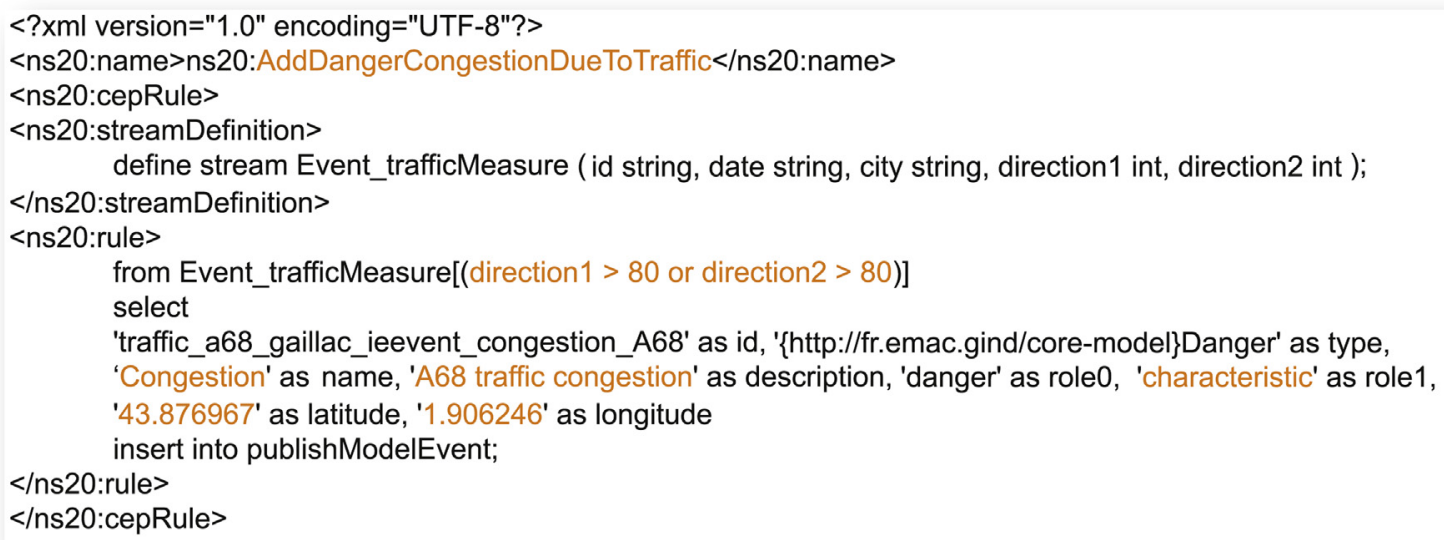

Fig. 7. The AddDangerCongestionDueToTraffic interpretation rule, stored in a XML file, written in SIDDHI QL.

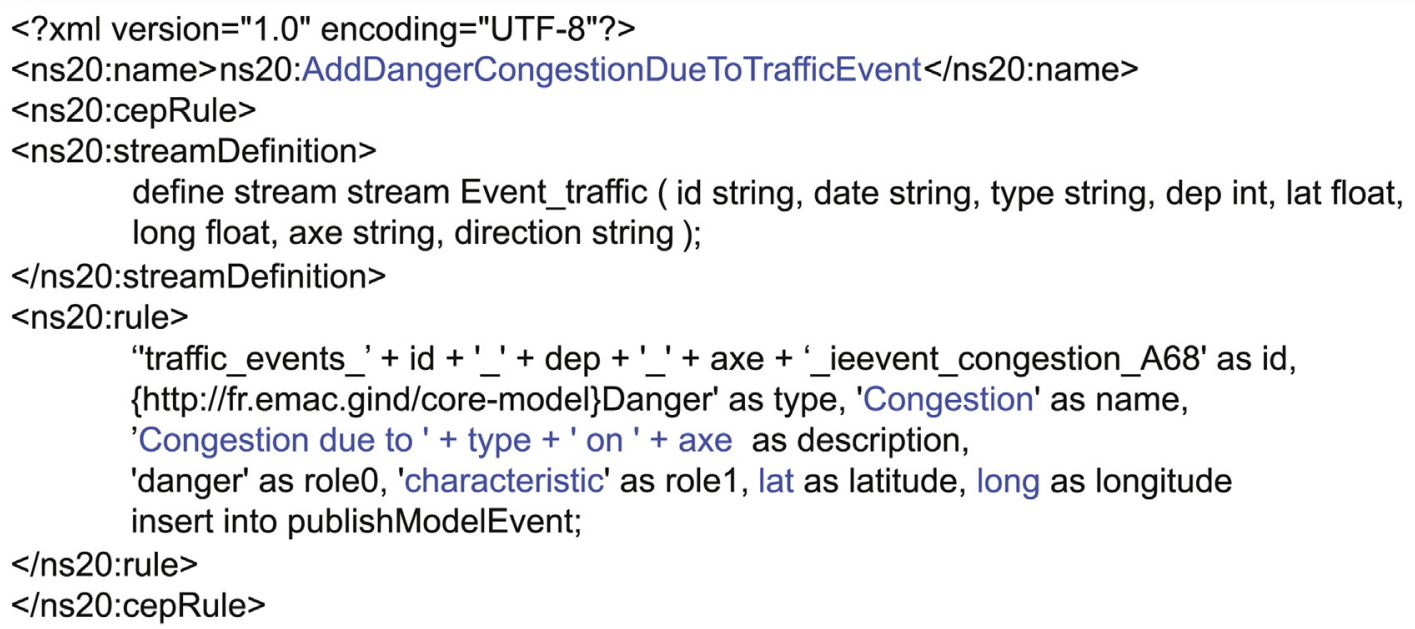

Fig. 8. The AddDangerCongestionDueToTrafficEvent interpretation rule, stored in a XML file, written in SIDDHI QL. 


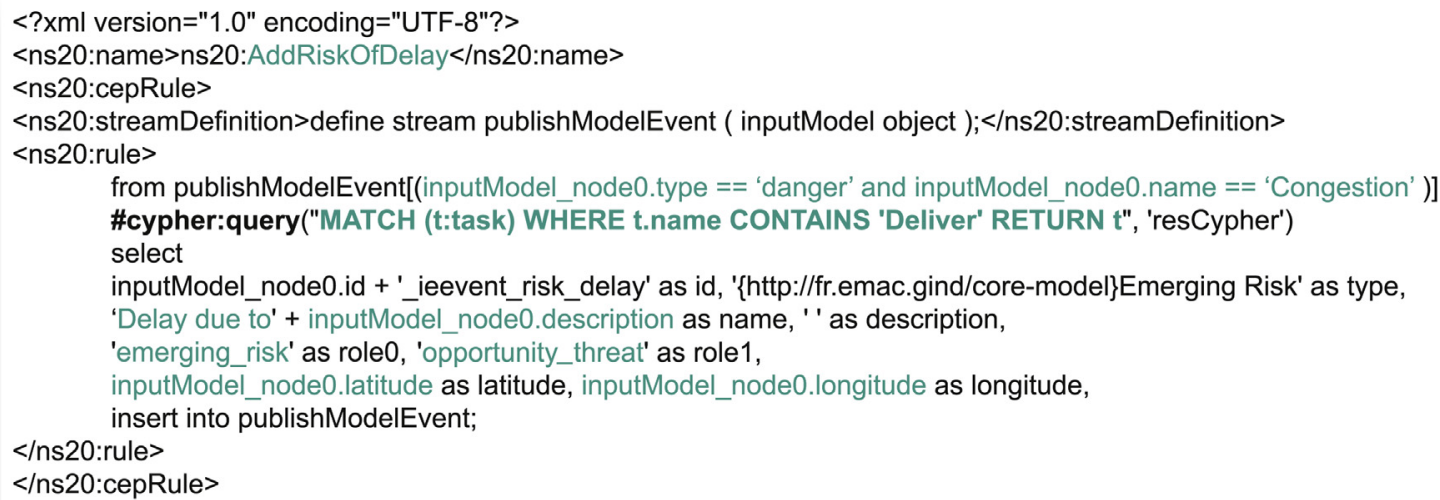

Fig. 9. The AddRiskOfDelay contextualization rule, stored in a XML file, written in SIDDHI QL.

Table 5

Results of the AIC information system when stressed with $1 \mathrm{k}$ events.

\begin{tabular}{lll}
\hline Interpretation delay & Dangers detected & Risks detected \\
\hline 0,9 s/event & $100 \%$ & $100 \%$ \\
\hline
\end{tabular}

\section{Results}

It takes a few days to download the code source of R-IOSUITE containing the AIC information system, design the whole model, write the rules of interpretation and contextualization, create synthetic data streams and record the use of the case study on video. The video is available at https://r-iosuite.com/display/RIOSUITE/ Demo+Video. The rest of this section presents (i) the user interfaces, (ii) the results and speed of the interpretation and contextualization of events and (iii) the ability of each component to control the 5 Vs of Big Data.

\subsection{The ability to enhance situation awareness}

Fig. 10 shows the two main interfaces seen by the logistics manager, when monitoring a logistics planning on R-IOSUITE.

Logistics managers can see the current logistics model on RIOPLAY, the geographical information system, at the top of Fig. 10. Any unexpected piece of information is automatically added on RIOPLAY and is underlined in red on R-IOTA. R-IOTA, on the bottom of Fig. 10, also enables to see the delivery process underway to fulfil the four orders of the pharmacies P1 and P2. Four tasks are in green: the two pharmaceutical establishments have completed their tasks. The four tasks in yellow have already been sent to the drivers responsible for delivering the drugs D1 and D2. The other four tasks have not yet started.

These two user interfaces, kept up to date by the AIC information system, give the appropriate pieces of information, at the right time, the right abstraction level and the right aggregation level to the supply chain managers. They thus automate their perception and directly contribute to their comprehension of the current logistics situation.

\subsection{The interpretation in real time}

The ability of the AIC information system to interpret the flow of events in real time was tested on a Web service transmitting a thousand traffic events at a frequency of two per second. The test was performed three times on a x64-based PC, Intel(R), core(TM) i5-8250U CPU, 1.60Ghz, $1800 \mathrm{MHz}$, four cores and eight logic processors. The results are displayed in Table 5.
Each event takes on average one second (16,6 minutes in total) to be interpreted, contextualized and displayed on the geographical information system (R-IOPLAY). All the events have been correctly interpreted by the 'Traffic event interpretation rule' and the detected dangers correctly stored inside the data base, and displayed to the supply chain managers. They then have then been correctly interpreted by the 'Congestion contextualisation rule' and the detected risks correctly store and display to the end users. The instances have been counted using the following Cypher Queries.

MATCH (d:danger) RETURN count (d)

MATCH ( $r$ :'Emerging risk') RETURN count(r)

\subsection{The control of the $5 \mathrm{Vs}$ of Big Data}

Each component of the AIC information system allows to manage at least one issue linked to the 5Vs of Big Data, listed in the introduction. The goal is to properly enhance the situation awareness of the AIC information system through the data interpretation, and the supply chain managers through the information contextualization. All the components and their effects are listed in the next five paragraphs.

The meta-model controls the variety and volume of information communicated to the logistics manager. The variety is limited by the finite number of concepts to be instantiated. The volume is limited by both the point of view and the scope of the supply chain.

The Complex Event Processing engine succeeds in reducing, with each event processing agent, the volume and velocity of the event streams available to the supply chain. Additionally, a rule assesses the reliability of an event based on the occurrence or absence of other events (veracity). The Complex Event Processing engine also enables a near real-time update of the geographical information system (velocity of actionable information): this was evaluated in the previous section.

Only a few concepts and Complex Event Processing rules are necessary to supervise a case study, regardless of the volume or variety of data to be processed. In addition, the meta-model and rules for processing complex events are modifiable and are easily adapted to the specifics of each supply chain. However, the veracity of the information (interpreted and contextualised) depend on the specificity of these rules.

The message broker enables to access a large variety and volume of event sources, through the subscription to topics: this enhances the potential veracity of the information interpreted from them.

In R-IOSUITE, the geographical information system enables the supply chain managers to add, delete or update any information contained in the current logistics model. This enhances the veracity 

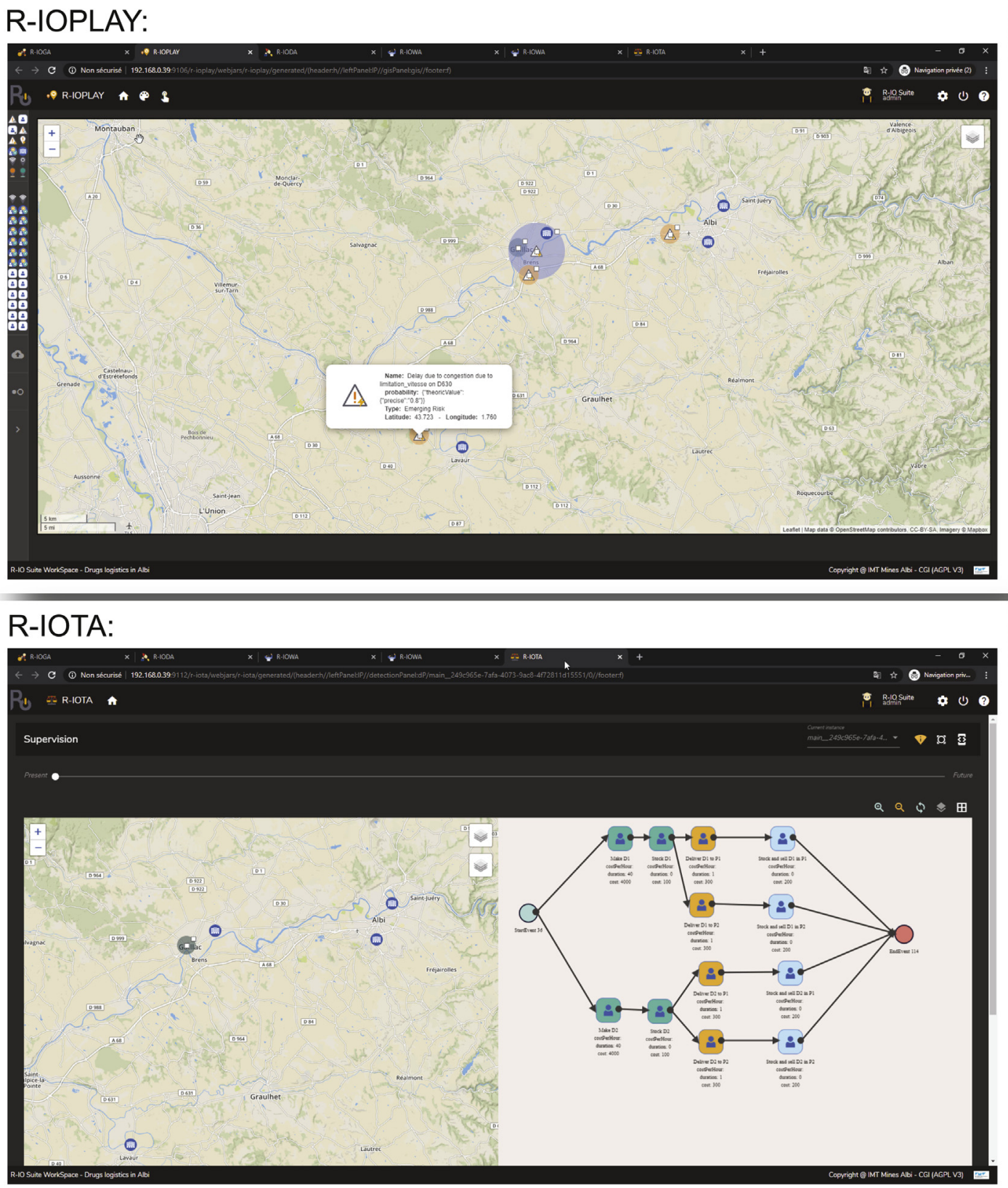

Fig. 10. The user interfaces which would be used by a logistics manager.

of the information processed by the system. In addition, layers can be used to adapt the the volume and variety of visible information.

To sum up, the AIC information system controls the volume (i.e. filter the input data) to obtain a better speed (i.e. for the interpretation) and use variety (i.e. of input data) to get better veracity (i.e. for output information).

\subsection{Outlook}

The AIC information system is not, in essence, dedicated to a particular area of collaboration. Therefore, abstraction built from crisis management can, as we see in this paper, apply to logistics. It could also be applied to other collaborative networks such as the planning of travelling visits for the nurse rostering problem.

\section{Conclusion}

This research work contributes to improve supply chain risk management through a context aware supply chain event management. Logistics managers can make use of our case study to try and translate their own context and business rules to monitor their supply chain with the AIC information system. This is a step towards a greater resilience for supply chains by making use of advances in recent digital technologies, but also for a better situation awareness for managers in the highly complex and volatile context of supply chains. Our contribution manages unexpected events by implementing a digital model of the supply chain, while enabling vital features of a Big Data environment. 
Of course, our case study still pales in comparison to a real supply chain case, for two main reasons: (i) we have not yet addressed a complex case with dozens of agents in the chain, or with a high volume of different data sources to put the system under stress and, (ii) we still need to take into account the veracity of information, in a context where a difference in credibility has an impact on decisionmaking.

While we answered the business issue described at the beginning of this paper, we must however take into account two other limitations to the effectiveness of our contributions. First, our work is still limited by the need of massive and open data sources. Improvements could be made with the generalised use of inventory and delivery tracking devices, such as RFID technology or IoT solutions. The second major limitation for our work is taking into account the consequences of risks in the supply chain, and the fact that choices made by logistics managers may have aftermaths on production or network capacities. One way to solve this issue would be to integrate a complete digital twin of the supply chain in order to simulate and forecast the impacts on the use of resources, and thus make a more informed decision.

\section{Funding sources}

None.

\section{Conflict of interest}

None.

\section{Authors' contribution}

Audrey Fertier and Guillaume Martin wrote the original draft. Audrey Fertier implemented the case study and evaluated the information system. Julien Lesbegueries, Nicolas Salatgé and Sébastien Rebière Pouyade implemented the information system and the decision support system. Anne-Marie Barthe Delanoë, Aurélie Montarnal, Frédérick Bénaben and Sébastien Truptil reviewed the paper and supervised the research work.

\section{Declaration of Competing Interest}

The authors report no declarations of interest.

\section{Acknowledgements}

We would like to thank the researchers and engineers from the CGI and LGC laboratories.

\section{References}

Ambulkar, S., Blackhurst, J., Grawe, S., 2015. Firm's resilience to supply chain disruptions: scale development and empirical examination. J. Oper. Manage. 33-34, 111-122, http://dx.doi.org/10.1016/j.jom.2014.11.002.

Baharmand, H., Comes, T., Lauras, M., 2017. Managing in-country transportation risks in humanitarian supply chains by logistics service providers: insights from the 2015 Nepal earthquake. Int. J. Disast. Risk Reduct. 24, 549-559, http://dx. doi.org/10.1016/j.ijdrr.2017.07.007.

Barthe-Delanoë, A.M., Truptil, S., Bénaben, F., Pingaud, H., 2014. Event-driven agility of interoperability during the Run-time of collaborative processes. Decis. Support Syst. 59, 171-179, http://dx.doi.org/10.1016/j.dss.2013.11.005.

Basdere, M., Caniglia, G., Collar, C., Rozolis, C., Chiampas, G., Nishi, M., Smilowitz, K., 2019. SAFE: a comprehensive data visualization system. INFORMS J. Appl. Analyt. 49, 249-261, http://dx.doi.org/10.1287/inte.2019.0989.

Benaben, F., Fertier, A., Montarnal, A., Mu, W., Jiang, Z., Truptil, S., BartheDelano\&rdquo;e, A.M., Lauras, M., Mace-Ramete, G., Wang, T., Bidoux, L., Lamothe, J., 2020. An AI framework and a metamodel for collaborative situations: application to crisis management contexts. J. Contingencies Crisis Manage. 28, 291-306, http://dx.doi.org/10.1111/1468-5973.12310.

Chappell, D., Liu, L., 2006. Web Services Brokered Notification. OASIS, OASIS Standard. Technical Report.
Charles, A., Lauras, M., Van Wassenhove, L., 2010. A model to define and assess the agility of supply chains: building on humanitarian experience. Int. J. Phys. Distrib. Logist. Manage. 40, 722-741, http://dx.doi.org/10.1108/ 09600031011079355.

Charles, A., Lauras, M., Van Wassenhove, L.N., Dupont, L., 2016. Designing an efficient humanitarian supply network. J. Oper. Manage. 47-48, 58-70, http://dx.doi.org / 10.1016/j.jom.2016.05.012.

Chen, D., Doumeingts, G., Vernadat, F., 2008. Architectures for enterprise integration and interoperability: past, present and future. Comput. Ind. 59, 647-659, http:// dx.doi.org/10.1016/j.compind.2007.12.016.

Danila, C., Stegaru, G., Stanescu, A.M., Serbanescu, C., 2016. Web-service based architecture to support SCM context-awareness and interoperability. J. Intell. Manuf. 27, 73-82, http://dx.doi.org/10.1007/s10845-014-0898-3.

Endsley, M.R., 1995. Measurement of situation awareness in dynamic systems. Hum. Fact. 37, 65-84, http://dx.doi.org/10.1518/001872095779049499.

Endsley, M.R., 2012. Designing for Situation Awareness: An Approach to UserCentered Design, 2nd ed. Taylor \& Francis, London; New York.

Fertier, A., Barthe-Delano\&Idquo;e, A.M., Montarnal, A., Truptil, S., Bénaben, F., 2020 A new emergency decision support system: the automatic interpretation and contextualisation of events to model a crisis situation in real-time. Decis. Support Syst., 113260, http://dx.doi.org/10.1016/j.dss.2020.113260.

Fertier, A., Montarnal, A., Barthe-Delano\&rdquo;e, A.M., Truptil, S., Bénaben, F., 2019 Real-time data exploitation supported by model- and event-driven architecture to enhance situation awareness, application to crisis management. Enterprise Inf. Syst. 0,1-28, http://dx.doi.org/10.1080/17517575.2019.1691268.

Flouris, I., Giatrakos, N., Deligiannakis, A., Garofalakis, M., Kamp, M., Mock, M., 2017. Issues in complex event processing: status and prospects in the Big Data era. J. Syst. Softw. 127, 217-236, http://dx.doi.org/10.1016/jjss.2016.06.011.

Graham, S., Hull, D., Murray, B., 2006. Web Services Notification (WSN). OASIS, OASIS Standard. Technical Report.

Gu, T., Pung, H.K., Zhang, D.Q., 2005. A service-oriented middleware for building context-aware services. J. Netw. Comput. Appl. 28, 1-18, http://dx.doi.org/10. 1016/j.jnca.2004.06.002.

Hofmann, E., Rüsch, M., 2017. Industry 4.0 and the current status as well as future prospects on logistics. Comput. Ind. 89, 23-34, http://dx.doi.org/10.1016/ j.compind.2017.04.002

Kamalahmadi, M., Parast, M.M., 2016. A review of the literature on the principles of enterprise and supply chain resilience: major findings and directions for future research. Int. J. Prod. Econ. 171, 116-133, http://dx.doi.org/10.1016/j.ijpe.2015. 10.023 .

Kim, K., Kim, H., Kim, S.K., Jung, J.Y., 2016. I-RM: an intelligent risk management framework for context-aware ubiquitous cold chain logistics. Expert Syst. Appl. 46, 463-473, http://dx.doi.org/10.1016/j.eswa.2015.11.005.

Laguna-Salvadó, L., Lauras, M., Okongwu, U., Comes, T., 2019. A multicriteria Master Planning DSS for a sustainable humanitarian supply chain. Ann. Oper. Res. 283 1303-1343, http://dx.doi.org/10.1007/s10479-018-2882-3.

L’Assemblée nationale, Le Président de la République, 2011. Loi relative au renforcement de la sécurité sanitaire du médicament et des produits de santé.

Lauras, M., Truptil, S., Bénaben, F., 2015. Towards a better management of complex emergencies through crisis management meta-modelling. Disasters 39, 687-714, http://dx.doi.org/10.1111/disa.12122.

Lu, H., Zhu, Y., Shi, K., Lv, Y., Shi, P., Niu, Z., 2018. Using adverse weather data in social media to assist with city-level traffic situation awareness and alerting. Appl. Sci. 8, 1193, http://dx.doi.org/10.3390/app8071193.

Luckham, D.C., Frasca, B., 1998. Complex Event Processing in Distributed Systems. Computer Systems Laboratory Technical Report CSL-TR-98-754. Stanford University, Stanford 28

Mörth, O., Emmanouilidis, C., Hafner, N., Schadler, M., 2020. Cyber-physical systems for performance monitoring in production intralogistics. Comput. Ind. Eng. 142 106333, http://dx.doi.org/10.1016/j.cie.2020.106333.

MSS, 2016. Rupture d'approvisionnement d'un médicament. https://solidaritessante.gouv.fr/soins-et-maladies/medicaments/professionnels-de-sante/ prescription-et-dispensation/article/rupture-d-approvisionnement-d-unmedicament.

MSS, 2017. Le circuit de distribution du médicament en France. https://solidaritessante.gouv.fr/soins-et-maladies/medicaments/le-circuit-du-medicament/ article/le-circuit-de-distribution-du-medicament-en-france.

Nguyen, T.H., Marmier, F., Gourc, D., 2013. A decision-making tool to maximize chances of meeting project commitments. Int. J. Prod. Econ. 142, 214-224, http:// dx.doi.org/10.1016/j.ijpe.2010.11.023.

Object Management Group, 2017. OMG ${ }^{\circledR}$ Unified Modeling Language ${ }^{\circledR}\left(\mathrm{OMG} \mathrm{UML}^{\circledR}\right)$.

Overbeek, S., Janssen, M., Tan, Y.H., 2012. An event-driven architecture for integrating information, processes and services in a plastic toys supply chain. International Journal of Cooperative Information Systems 21, 343-381, http:// dx.doi.org/10.1142/S0218843012500062.

Papadopoulos, T., Gunasekaran, A., Dubey, R., Altay, N., Childe, S.J., Fosso-Wamba, S., 2017. The role of Big Data in explaining disaster resilience in supply chains for sustainability. J. Clean. Prod. 142, 1108-1118, http://dx.doi.org/10.1016/j. jclepro.2016.03.059.

Perera, C., Zaslavsky, A., Christen, P., Georgakopoulos, D., 2014. Context aware computing for the internet of things: a survey. IEEE Commun. Surveys Tutor. 16, 414-454, http://dx.doi.org/10.1109/SURV.2013.042313.00197, First.

Ponomarov, S.Y., Holcomb, M.C., 2009. Understanding the concept of supply chain resilience. Int. J. Logist. Manage. 20, 124-143, http://dx.doi.org/10.1108/ 09574090910954873. 
Pramanik, M.I., Lau, R.Y.K., Demirkan, H., Azad, M.A.K., 2017. Smart health: Big data enabled health paradigm within smart cities. Expert Syst. Appl. 87, 370-383, http://dx.doi.org/10.1016/j.eswa.2017.06.027.

Richey, R.G., Morgan, T.R., Lindsey-Hall, K., Adams, F.G., 2016. A global exploration of Big Data in the supply chain. Int. J. Phys. Distrib. Logist. Manage. 46, 710-739, http://dx.doi.org/10.1108/IJPDLM-05-2016-0134.

Salatgé, N., Rebière-Pouyade, S., Lesbegueries, J., Fertier, A., 2020. R-IOSuite V2. 3 [Computer software]. IMT Mines Albi http://r-iosuite.com/.

Schoenherr, T., Speier-Pero, C., 2015. Data science, predictive analytics, and big data in supply chain management: current state and future potential. J. Bus. Logist. 36, 120-132, http://dx.doi.org/10.1111/jbl.12082.
Tejada, P.R., Jung, J.Y., 2013. Context-Aware Dynamic Event Processing Using Event Pattern Templates. IEICE Trans. Inf. Syst. E96-D, 1053-1062.

Vambenepe, W., Graham, S., Niblett, P., 2006. Web Services Topics. OASIS, OASIS Standard. Technical Report.

Vlahakis, G., Apostolou, D., Kopanaki, E., 2018. Enabling situation awareness with supply chain event management. Expert Syst. Appl. 93, 86-103, http://dx.doi org/10.1016/j.eswa.2017.10.013.

Wen, T., Mihăiță, A.S., Nguyen, H., Cai, C., Chen, F., 2018. Integrated incident decisionsupport using traffic simulation and data-driven models. Transport. Res. Rec. 2672, 247-256, http://dx.doi.org/10.1177/0361198118782270. 